\title{
GAUGING THE BOUNDARIES OF SECOND LANGUAGE COMPETENCE: A STUDY OF LEARNER JUDGMENTS
}

\author{
Bradford Arthur ${ }^{1}$ \\ The University of Michigan
}

\begin{abstract}
Second language learners can make judgments as to the acceptability of verbal sequences in a target language text. However, such judgments are often different from judgments of the same text by native speakers of the target language. These differences can be interpreted as a gauge of differences between the learners' transitional competence and the competence of native speakers. Similarly, changes in learner judgments may indicate changes in transitional competence. The latter part of this paper reports a study in which learner judgments are used to test a model of change in learner competence proposed by S. Pit Corder (1971) and an extension of that model proposed by Jacquelyn Schachter, Adele F. Tyson, and Frank J. Diffley (1976).
\end{abstract}

\section{INTRODUCTION}

A number of studies over the past decade have used error analysis as a technique for measuring changes in the transitional competence of second language learners. Such studies-including Dulay and Burt (1974), Ravem (1974), Swain (1976), and Tarone, Frauenfelder, and Selinker (1976)assume that a change in the frequency of a particular error in the spoken or written language of the learner can indicate a change in the transitional competence of that learner; the fewer the errors or the lower the frequency of a particular error, the closer the transitional competence of the learner is to the competence of a native speaker.

In most error-analysis-based studies, the learners' competence is reflected in the language they produce; the researchers' in the judgments they make. But learners can also make judgments, evaluating the acceptability of a target language corpus and correcting what they perceive as errors in that corpus. Two studies--Schachter, Tyson, and Diffley (1976) and Tucker and Sarofim (1979)-use judgments of acceptability to compare the reactions of

1 I am grateful to Larry Selinker, Alexander H. Urquhart, and Miles D. Woken for their comments on earlier versions of this paper. I am additionally grateful to Sally $S$. Criss for her assistance with a pilot study preliminary to the study reported here. I am especially indebted to Susan Dycus for her assistance with the collection and analysis of data for the study reported here and for her careful and critical reading of an early draft of this paper. An abbreviated version of this paper was presented at the Third Los Angeles Second Language Research Forum, UCLA, February 29, 1980. 
nonnative speakers from different first language groups to the same set of target language errors and to compare those responses with the responses of native speakers. Neither of these studies, however, considers developmental changes in second language learners' judgments of target language errors.

One sort of developmental change in learner judgments is noted by d'Anglejan-Chatillon (1975). In contrasting students at two proficiency levels, she notes that only the more advanced students produced nonrandom judgments of the deviance of test sentences. She concludes that less advanced students "were not able to discriminate between normal and deviant sentences." (p. 59) Her results suggest that a comparison of judgments made by learners at different stages in their mastery of a second language can reveal changes in developing competence. Moreover, such a comparison provides a view of some areas of transitional competence that in a typical error analysis are obscured by avoidance strategies. The present paper develops a model for interpreting learners' judgments of their target language and also describes some preliminary research based on that model.

\section{A MODEL OF LEARNER JUDGMENTS}

Language learners can and do judge the grammaticality of sentences in the language they are learning, but the judgments made by learners frequently do not match the judgments made by native speakers. Paradoxically, the "errors" made by second language learners are, from the learner's own perspective, not errors at all, and second language learners may reject constructions that from a native speaker's perspective are acceptable. This paradox muddles some of the standard terminology. References to a language sequence as "grammatical" or "ungrammatical," "acceptable" or "unacceptable," "correct" or "erroneous," are not clear unless we know who is making the judgments. I have therefore adopted the convention of using adjectival suffixes $(\mathrm{N})$ and $(\mathrm{L})$ to mean respectively "from a native speaker's viewpoint" and "from a language learner's viewpoint." Thus, to say that a language sequence is unacceptable (L) is to say that it is judged unacceptable by a language learner.

The relationship between the judgments of a learner and the judgments of a native speaker is represented in part by the Venn diagram in Figure $1 .^{2}$ In

\footnotetext{
${ }^{2}$ Venn diagrams are useful in providing a graphic representation of the relationship among sets. The enclosed space (SS) is defined as containing the universal set of all
} 


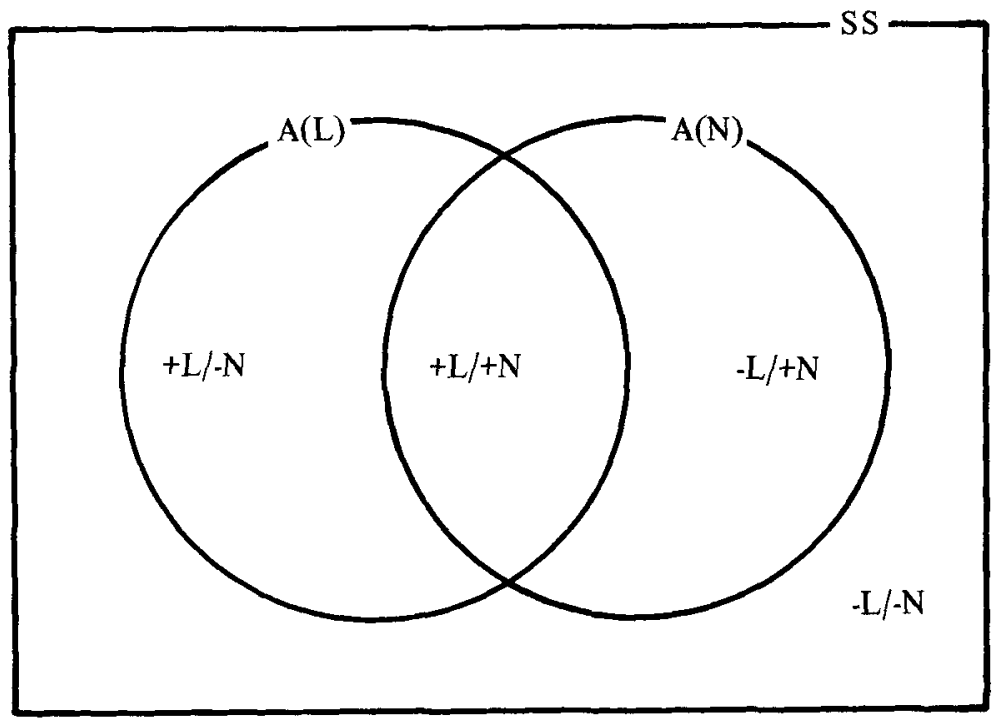

Figure 1. Diagram of the acceptability judgments of a native speaker and a learner of language $L$ 
this diagram, the area within SS represents all possible sequences of speech sounds. The area within $\mathrm{A}(\mathrm{N})$ here represents those sequences judged acceptable by a native speaker of language $L$. The sequences within the circle $\mathrm{A}(\mathrm{L})$ are those judged acceptable by a learner of language $\mathrm{L}$. Those sequences within the area common to $\mathrm{A}(\mathrm{L})$ and $\mathrm{A}(\mathrm{N})($ area $+L /+N)$ represent those sequences that are both acceptable $(\mathrm{N})$ and acceptable $(\mathrm{L})$; those sequences in area $+L /-N$ are acceptable (L) but unacceptable $(\mathrm{N})$; and those sequences within area $-L /+N$ are acceptable (N) but unacceptable (L). Sequences within area $-L /-N$ are unacceptable $(\mathrm{L})$ and also unacceptable $(\mathrm{N})$.

I assume that as learners advance in their knowledge of the target language, their judgments will become closer to those of a native speaker. The series of Venn diagrams in Figure 2 illustrates this process of change. The three diagrams represent three stages in an imaginary learner's mastery of English. At stage 1, the sequence Life is a tale what is told by an idiot is among the sequences that the learner judges as acceptable. Also at stage 1 , the sequences Life is a tale is told by an idiot, Life is a tale that is told by an idiot, and Life is a tale told by an idiot are among the sequences that the learner judges as unacceptable. A native speaker's judgments are represented by the righthand circle in each diagram. At stage 1, the native speaker's judgments are almost the opposite of the learner's: to the native speaker, Life is a tale is told by an idiot and Life is a tale what is told by an idiot are unacceptable whereas the other two sequences are acceptable.

At stage 2, the circle representing the learner's judgments has shifted closer to that of the native speaker. At this stage, the learner would reject as unacceptable the sequences Life is a tale is told by an idiot and Life is a tale told by an idiot but would accept the other two sequences. At stage 3 , the learner's judgments have again moved closer to those of the native speaker with the consequence that the learner would at that stage reject Life is a tale what is told by an idiot. At stage 3 the learner would still also reject the grammatical $(\mathrm{N})$ sequence Life is a tale told by an idiot and the ungrammatical $(\mathrm{N})$ sequence Life is a tale is told by an idiot.

Figure 2 represents changes in learner judgments. The research reported here assumes that these changes are related to two other sorts of changes: changes in the target language sequences that the learner produces and changes in the learner's competence. The first assumption is that the

possible language sequences. Circles within that space contain various subsets of sequences. Overlapping circles indicate sets with some shared members. This diagramming convention should not be confused with a superficially similar convention adopted by Schachter, Tyson, and Diffley (1976). 

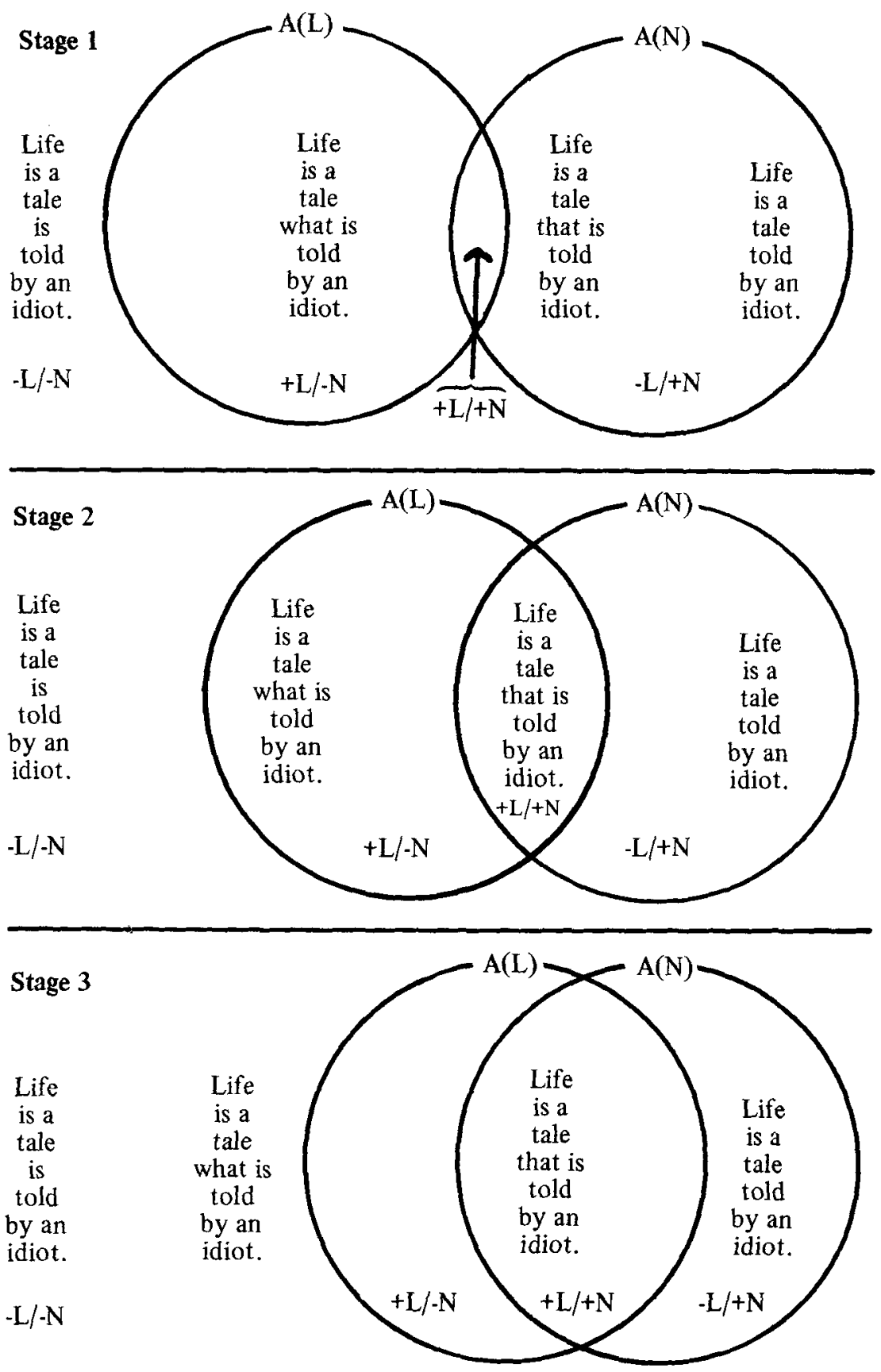

Figure 2. Hypothetical stages in learner judgments 
sequences the learner judges as acceptable will belong to roughly the same set as those he or she uses when speaking the target language. Obviously this correspondence will not always hold, but I am assuming that it does hold in a significant majority of cases. I am assuming, in other words, that the hypothetical learner at stage 1 of Figure 2 could conceivably say something like Life is a tale what is told by an idiot but would avoid saying all three of the other sequences and sequences like them.

I am also assuming that learner judgments of acceptability are in part a reflection of that learner's competence in the target language. I am assuming, in other words, that one important reason why learners judge a sequence to be acceptable is that such a sequence is in accord with their internalized knowledge of the target language structure. Again, in terms of the diagrams in Figure 2, I am assuming that the boundaries defined by $\mathrm{A}(\mathrm{L})$ correspond, at least in a rough sense, to the boundaries of the learner's competence, so that the changes in those boundaries between stage 1 and stage 3 indicate an increasing similarity between the learner's competence and the competence of a native speaker. This interpretation of the diagram as representing changes in learner competence is identical with the interpretation suggested by Corder (1971).

But there is a crucial difference between Corder's use of the diagram to represent shifting competence on the one hand and, on the other hand, its use here to represent the judgments that learners make or the sentences they produce. Learner judgments and learner utterances can be observed, collected, and studied directly. A learner's competence can be studied only indirectly through introspection or through events in the physical world assumed to be associated with it. In the research reported here, I assume that learner judgments of responsibility as well as the utterances that learners produce can serve as gauges of learner competence.

Such gauges are useful, but they must be read intelligently since judgments of acceptability are not solely a reflection of differences in language competence. They may also reflect differences in such things as the judges' patience, their understanding of their task, and the "rules" of grammar they have been taught. To some extent these other influences on judgments can be controlled by the careful design of elicitation procedures and by the use of statistical techniques that separate the effects of different sources of variation. The appropriateness of using learners' language behavior as evidence for the structure of their competence is discussed further in Arthur (1980).

Learners' judgments and learners' utterances provide different, and in some respects complementary, evidence concerning their competence. 
Learners' utterances give us direct evidence that a given sequence is within $A(L)$ but no direct evidence that any given sequence is outside $A(L)$ (see Figure 1). The fact that a learner has not uttered some particular target language sequence does not exclude it from the set of sequences that he or she might have uttered. On the other hand, when a learner judges a sequence as unacceptable, we have direct evidence that the sequence is outside $A(L)$ and thus, we might assume, outside the learner's competence.

Although learners can judge certain sequences as acceptable or unacceptable in the target language, they may be unable to decide whether some other sequences are acceptable or not. Schachter, Tyson, and Diffley (1976) claim that as second language acquisition progresses, the number of such indeterminate sequences decreases. Indeterminate sequences can be represented in a Venn diagram by making the modifications indicated in Figure 3. In the diagram presented in Figure 3, the area enclosed by $\mathrm{A}(\mathrm{L})$ is supposed to contain those sequences that the learner judges to be acceptable in the target language. The area outside $\mathrm{I}(\mathrm{L})$ is supposed to contain those sequences the learner judges unacceptable. The shaded area inside $I(L)$ but outside $A(L)$ is supposed to contain sequences the acceptability of which the learner is unable to judge. Schachter, Tyson, and Diffley suggest that as language learning progresses, the size of the shaded area decreases.

The experiment described below was designed to test the accuracy of four hypotheses:

Hypothesis 1: As a learner's knowledge of a foreign language grows, the number of sequences in the set $+L /-N$ (see Figure 1) will decrease.

Hypothesis 2: As a learner's knowledge of a foreign language grows, the number of sequences in the set $-L /+N$ will decrease.

Hypothesis 3: As a learner's knowledge of a foreign language grows, the number of sequences in the set $+L /+N$ will increase.

Hypothesis 4: As a learner's knowledge of a foreign language grows, the number of indeterminate sequences (the shaded area in Figure 3) will decrease.

The first three of these hypotheses are derived from the Venn diagram model proposed originally by Corder and reinterpreted here to represent changes in learner judgments and the utterances that learners produce as well as changes in learner competence. The last hypothesis is derived from Schachter's statements concerning changes in the extent of indeterminacy in learner interlanguage. 


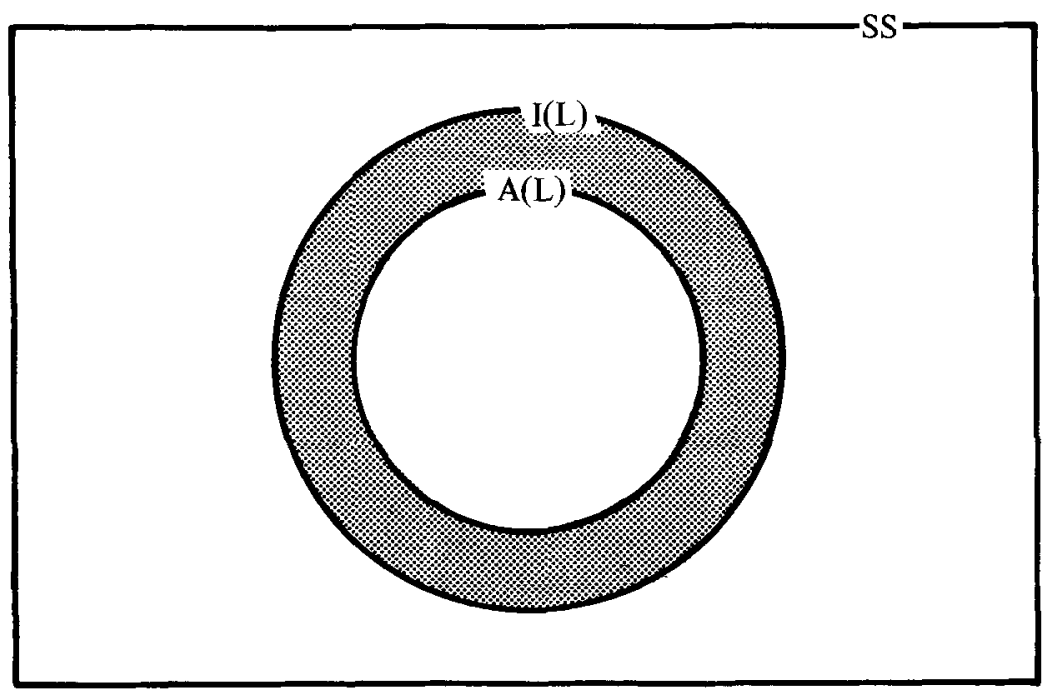

Figure 3. A Venn diagram representing acceptability judgments including indeterminacy 


\section{PROCEDURE}

The subjects for this study were 149 learners of English as a second language. All were adults studying at the University of Michigan's English Language Institute during the fall of 1978. Students at the institute were assigned to one of six class levels based on an objective, multiple-choice test covering grammar, vocabulary, and written and oral comprehension. The experimental task was considered too difficult for the two lowest class levels. All students at the remaining four levels (lower-intermediate through higheradvanced) served as subjects. Table 1 describes some of the characteristics of those students and shows the distribution of students within the four class levels.

Chi square analyses of the groupings in Table 1 indicate a proportionate distribution of men and women and also of various first language groups among the four class levels. However, there was a disproportionately large number of older students in the higher-advanced section.

As an in-class editing activity, each of these students was asked to read over the passage printed below and to "underline and correct all errors." Eighteen errors typical of the sorts of structural mistakes found in the speech and writing of adult learners of English were introduced into the text. These errors are underlined in the version of the text presented below.

In a pilot version of this activity, the instructions were: "Read through this passage and underline words or phrases that you think may contain an error. Whenever possible, write in corrections for the errors you have underlined." It was assumed that students would recognize more errors than they would be able to correct. However, in the pilot study, virtually all of the errors that were underlined were also corrected (L). The two tasks, underlining and correcting, were therefore combined in the final version of the instructions.

It was assumed that at least some of these errors might fall within the set of sequences represented by area $+L /-N$ in Figure 1. Such errors would not be identified by learners. It was likewise assumed that some of the sequences in the passage would fall within area $-L /+N$. Such sequences would be corrected by the learners but not by the native speakers. A text written entirely in the interlanguage of the learner would contain no sequences in area $-L /+N$; a text written entirely in the native speaker's dialect would contain no sequences in area $+L /-N$. Consequently, a text appropriate for this sort of analysis must contain unshared sequences from both dialects.

Finally, it was assumed that native speakers would agree for the most part 
Table 1

Characteristics of subjects by class level

\begin{tabular}{|c|c|c|c|c|c|}
\hline \multirow[b]{2}{*}{$\begin{array}{l}\text { Subject } \\
\text { groupings }\end{array}$} & \multicolumn{4}{|c|}{ Class level } & \multirow[b]{2}{*}{ Total } \\
\hline & $\begin{array}{l}\text { Lower } \\
\text { inter- } \\
\text { mediate }\end{array}$ & $\begin{array}{l}\text { Higher } \\
\text { inter- } \\
\text { mediate }\end{array}$ & $\begin{array}{l}\text { Lower } \\
\text { ad- } \\
\text { vanced }\end{array}$ & $\begin{array}{l}\text { Higher } \\
\text { ad- } \\
\text { vanced }\end{array}$ & \\
\hline $\begin{array}{l}\text { All } \\
\text { students }\end{array}$ & 48 & 32 & 32 & 37 & 149 \\
\hline $\begin{array}{l}\text { Sex: } \\
\quad \text { women } \\
\text { men }\end{array}$ & $\begin{array}{l}18 \\
30\end{array}$ & $\begin{array}{r}8 \\
24\end{array}$ & $\begin{array}{l}12 \\
20\end{array}$ & $\begin{array}{l}11 \\
26\end{array}$ & $\begin{array}{r}49 \\
100\end{array}$ \\
\hline $\begin{array}{l}\text { Language: } \\
\text { Spanish } \\
\text { Arabic } \\
\text { Japanese } \\
\text { other }\end{array}$ & $\begin{array}{r}15 \\
8 \\
16 \\
9\end{array}$ & $\begin{array}{l}9 \\
6 \\
8 \\
9\end{array}$ & $\begin{array}{r}11 \\
9 \\
5 \\
7\end{array}$ & $\begin{array}{r}11 \\
6 \\
12 \\
8\end{array}$ & $\begin{array}{l}46 \\
29 \\
41 \\
33\end{array}$ \\
\hline $\begin{array}{l}\text { Age: } \\
\begin{array}{l}15 \text { to } \\
24 \text { years } \\
25 \text { years } \\
\text { and over }\end{array}\end{array}$ & 26 & 19 & 19 & 11 & 75 \\
\hline
\end{tabular}


as to which sequences contained errors and which sequences did not. This assumption concerning native speakers was tested informally and found to be substantially correct, although native speakers did occasionally miss errors (due presumably to inadvertence rather than ignorance) and also occasionally made stylistic "improvements" in the text. One reason for the agreement among native speakers is that the errors are embedded in a coherent discourse rather than in a series of semantically unrelated sentences. Native speakers might disagree on the acceptability of $I$ suggested that he made himself at home if that sequence were considered in isolation; but it certainly is not acceptable $(\mathrm{N})$ in the context of the passage.

The passage was presented to the subjects with triple spacing to facilitate corrections and, of course, without underlining. Students were given ample time (20-30 minutes) to complete the editing task. They were not told how many errors the text contained.

An old friend from the California, who were going to spend a few days with me, called from the airport___tell me that he had arrived. I was not able to leave an office, but I had made plans for him arrival. I told him when my new house was, and I tell him that I had left the key under the doormat. Since I knew it would be pretty late before I could get home, I suggested that he made himself at home and help herself to anything in the refrigerator.

Two hours later my friend phoning me from the house. He said that him was listening to some of my records after eating __delicious meal. I asked him if he has any difficulty finding the key. He answered, "I couldn't to find the key under the doormat, but fortunately, the living room window by the apple tree was open, so I climbed in through window." I listening to all this in astonishment. There is no apple tree outside my window, but there are one by the living room window that is my next-door neighbor's house.

The following five tabulations were made for each edited passage:

1. The total number of errors $(\mathrm{N})$ (of the 18 underlined above) perceived as errors ( $\mathrm{L}$ ) by the student

2. The total number of non-errors $(\mathrm{N})$ perceived as errors (L) by the student

3. The total number of errors (L)-the sum of 1 and 2 above

4. The percentage of underlined errors $(\mathrm{N})$ altered so as to produce grammatically correct $(\mathrm{N})$ English 
5. The percentage of underlined non-errors $(\mathrm{N})$ altered so as to produce grammatically correct $(\mathrm{N})$ English

In tabulations 3 and 4 , a wide variety of different corrections were accepted. For example, the third error, “. . . called from the airport___ tell me . . .," might have been corrected by changing "tell" to "to tell" or to "and told." As anticipated, virtually every error that was underlined was also corrected, although not always appropriately (N).

\section{RESULTS}

Table 2 presents the mean scores and standard deviations for each of the four class levels on each of the five counts described above. A least-squares regression analysis (see Table 2) indicated that the differences between levels are significant well below the .001 level for average number of perceived errors $(\mathrm{N})$, average number of perceived non-errors $(\mathrm{N})$, and percentage of non-errors $(\mathrm{N})$ corrected to non-errors $(\mathrm{N})$. There was, however, no significant change in the percentage of errors $(N)$ corrected to non-errors $(N)$, nor was there a significant change in the average number of errors underlined, i.e., total errors (L).

These same results are shown graphically in Figures 4 and 5. As Figure 4 indicates, students became progressively better at identifying the errors $(N)$ in the text. At the same time there was a progressive decrease in the number of non-errors (N) that they perceived as errors. The net result was that the total number of errors (L) remained virtually the same.

The situation characterized in Figure 5 is somewhat different. The mean percentage of errors $(N)$ corrected to non-errors $(N)$ remained high for all four class levels. When students recognized an error $(\mathrm{N})$, they were able to correct it appropriately $(\mathrm{N})$ in the vast majority of cases. But those same students, in correcting non-errors $(\mathrm{N})$, more often than not changed the text so that the previously grammatical $(N)$ segment was rendered ungrammatical $(\mathrm{N})$. This tendency to introduce errors $(\mathrm{N})$ in the process of editing was most pronounced at lower proficiency levels. Lower-intermediate students, in changing the text to eliminate errors (L), introduced errors (N) more than 77 percent of the time. At the higher-advanced level, this percentage decreased significantly to less than 55 percent.

Additional analyses of variance were performed to determine the possible effect of differences in sex, native language, and age on the four measurements. No significant differences were found. It is therefore assumed that the 
Arthur

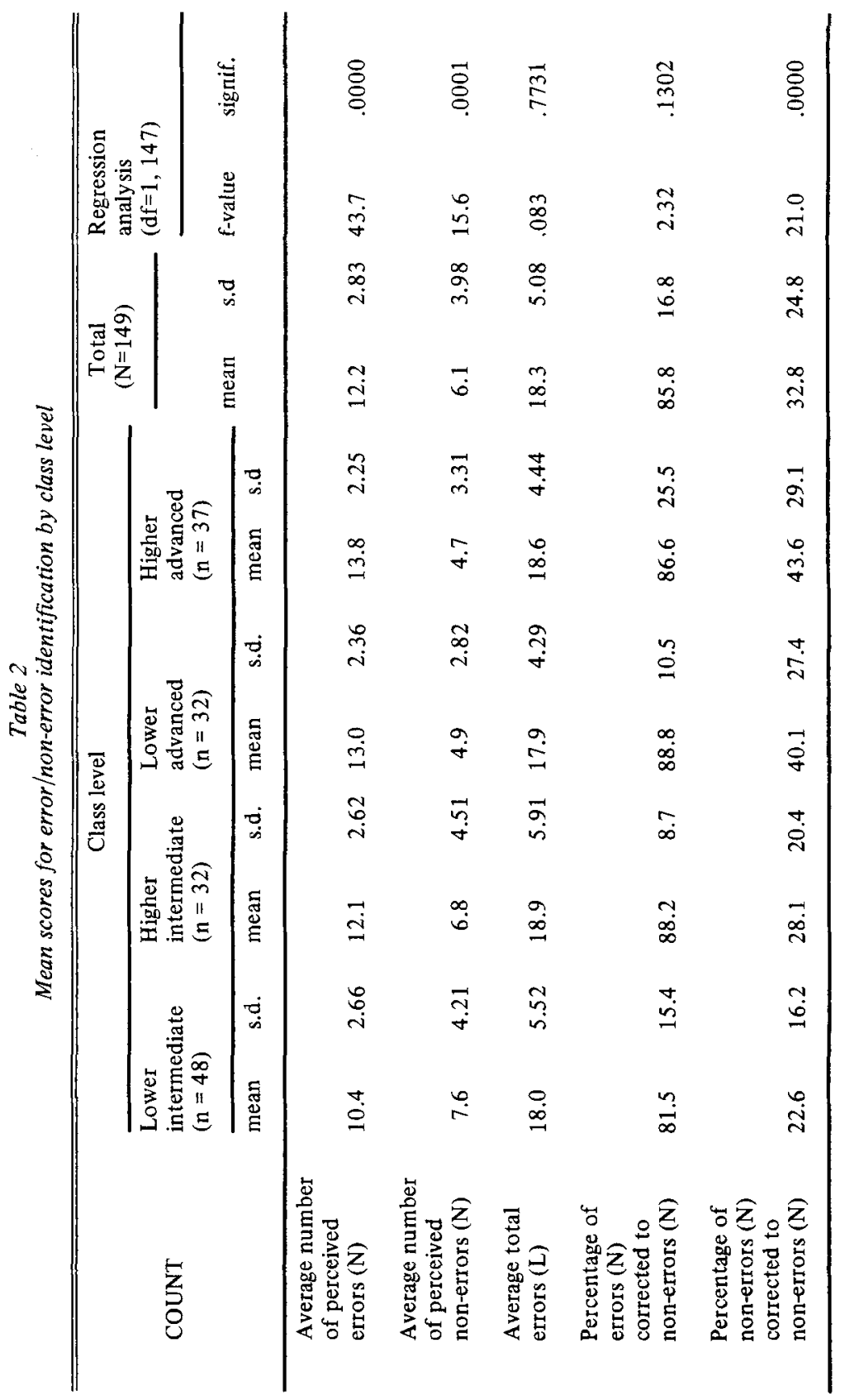




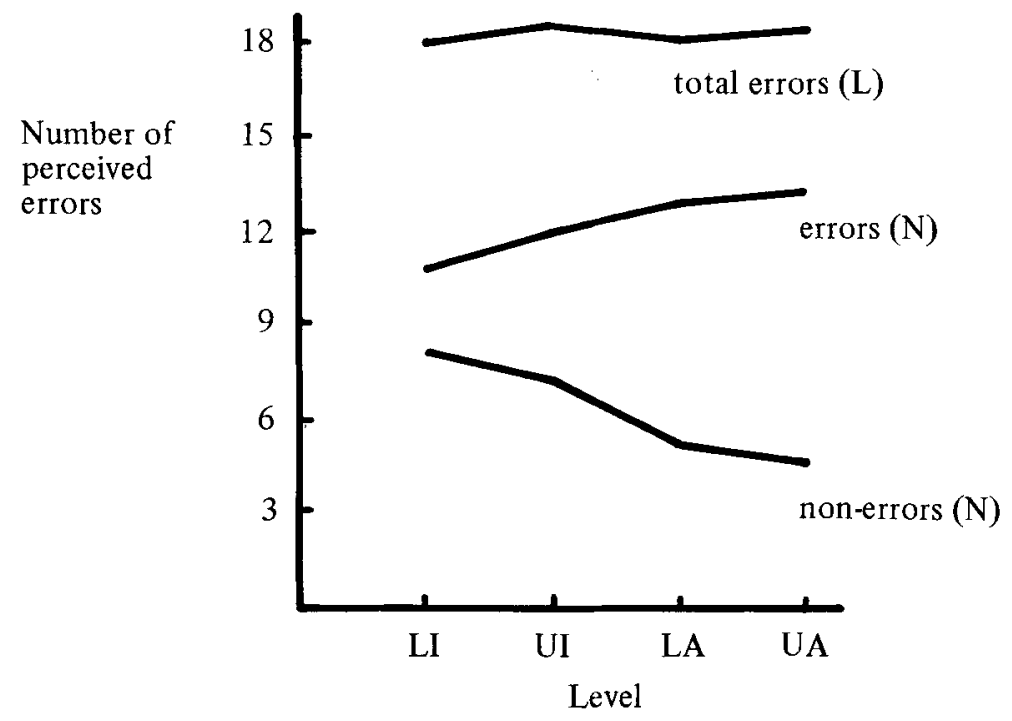

Figure 4. Total perceived errors and non-errors

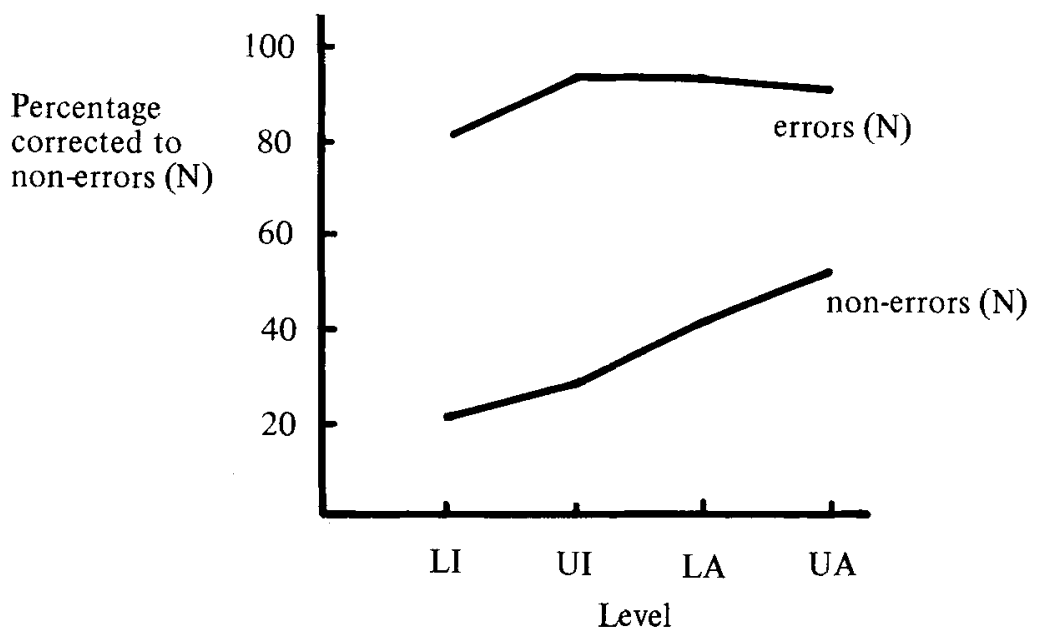

Figure 5. Mean percentage of errors and non-errors appropriately (N) corrected 
disproportionately large number of older students in the higher-advanced classes did not contribute to the changes noted above.

\section{DISCUSSION}

This study was intended as a partial test of the four hypotheses enumerated above. In considering the implications of the study, we shall discuss each hypothesis separately.

Hypothesis 1: As a learner's knowledge of a foreign language grows, the number of sequences in the set $+L /-N$ will decrease. As the boundaries of $\mathrm{A}(\mathrm{L})$ shift toward those of $\mathrm{A}(\mathrm{N})$, sequences previously in area $+L /-N$ appear in area $-L / N$. The sequence Life is a tale what is told by an idiot in Figure 2 illustrates the consequences of this shift. At stage 2 , that sequence appears in the area of the diagram designated $+L /-N$; by stage 3 , the shifting boundaries of $\mathrm{A}(\mathrm{L})$ have caused that sequence to be reclassified $-L /-N$. Since these sequences are, after the shift, outside $A(L)$, they are recognized as errors by the learner. Consequently, as the size of area $+L /-N$ decreases in the process of language acquisition, there will be an increase in the number of errors (N) that are marked as errors by the learner. Such an increase was observed in the present study, as indicated by the middle curve in Figure 4. Hypothesis 1 is therefore supported by the experimental results reported above.

Hypothesis 2: As a learner's knowledge of a foreign language grows, the number of sequences in the set $-L /+N$ will decrease. As the boundaries of $\mathrm{A}(\mathrm{L})$ shift toward those of $\mathrm{A}(\mathrm{N})$, sequences previously in the area $-L /+N$ shift into area $+L /+N$. The sequence Life is a tale that is told by an idiot in Figure 2 illustrates the consequences of this shift. At stage 1 it appears in the area of the diagram designated $-L /+N$; by stage 2 , the shifting boundaries of $\mathrm{A}(\mathrm{L})$ have caused that sequence to be reclassified $+L /+N$. When such a shift occurs, the sequences become grammatical (L) and therefore would not be corrected by the learner. Consequently, as learners advance in their mastery of the target language, they should correct progressively fewer of the sequences that are non-errors $(\mathrm{N})$. Such a decrease in the number of corrected non-errors $(\mathrm{N})$ was observed in the present study, as indicated by the bottom curve of Figure 4. Hypothesis 2 is therefore also supported by the experimental results reported above.

Hypothesis 3: As a learner's knowledge of a foreign language grows, the number of sequences in the set $+L /+N$ will increase. As the boundaries of $A(L)$ shift toward those of $A(N)$, the portion of $A(L)$ taken up by area 
$+L /+N$ increases, whereas the portion taken up by area $+L /-N$ decreases. This change in the relative sizes of $+L /-N$ and $+L /+N$ is illustrated in Figure 2. Note that as $A(L)$ shifts from stage 1 to stage 3 , the portion of $A(L)$ that is inside $A(N)$ increases, whereas the portion outside $A(N)$ decreases. Consequently, the model predicts that as the learner corrects sequences that fall outside $A(L)$ to sequences within $A(L)$, his or her corrected sequences should fall with increasing frequency in that portion of $\mathrm{A}(\mathrm{L})$ that is $+L /+N$ rather than in the portion of $\mathrm{A}(\mathrm{L})$ that is $+L /-N$. Again, Figure 2 will make this assertion more concrete. At all three of the stages represented in Figure 2, the strings Life is a tale is told by an idiot and Life is a tale told by an idiot are outside $A(L)$. Consequently, the model predicts that at all three stages the learner would correct these sequences to some sequence within $\mathrm{A}(\mathrm{L})$. At stage 1 , the sequence resulting from that correction would probably be outside $\mathrm{A}(\mathrm{N})$; perhaps it would be the sequence Life is a tale what is told by an idiot. By stage 2, if the model is accurate, there should be a better chance that the learner's correction would result in a sequence like Life is a tale that is told by an idiot, a string within $\mathrm{A}(\mathrm{N})$. But notice that a correction to Life is a tale what is told by an idiot is still possible at stage 2 . That possibility no longer exists at stage 3 .

To evaluate hypothesis 3 , we will first consider non-errors $(\mathrm{N})$ corrected by the learners in the experiment. Such sequences correspond to sequences like Life is a tale told by an idiot in Figure 2. The model would predict that the correction of such non-errors $(\mathrm{N})$ should occur with increasing frequency in strings that are also non-errors $(\mathrm{N})$. As indicated by the lower curve in Figure 5, the present study confirms that prediction.

To continue our evaluation of hypothesis 3 , we next consider errors $(\mathrm{N})$ corrected by learners in the present study. Such sequences correspond to sequences like Life is a tale is told by an idiot in Figure 2. The model would predict that the correction of errors (N) should occur with increasing frequency in strings that are non-errors $(\mathrm{N})$. This prediction is not confirmed by the present study. As the upper curve in Figure 5 indicates, the frequency of non-errors $(\mathrm{N})$ resulting from such corrections is constant and, as noted earlier, surprisingly high.

A possible explanation for this apparent failure of the model to predict the experimental results might be found in the characteristics of the errors (N) introduced into the sample passage. These errors are special in at least two respects. First, they are all the sort of errors likely to have occurred at an earlier stage of the subjects' own English interlanguage. Second, the errors (N) introduced into the test passage are almost all examples of the errors 
that students in ESL classes are taught to correct. It seems likely, but impossible to determine without further testing, that a different, less restricted selection of errors $(\mathrm{N})$ would have produced a positive slope for the upper curve of Figure 5.

Hypothesis 4: As a learner's knowledge of a foreign language grows, the number of indeterminate sequences will decrease. In terms of the Venn diagram represented in Figure 3, as the transitional competence of the learner advances, the shaded area will shrink, and consequently the number of sequences in the area outside I(L) will increase. In terms of the present study, as proficiency in English increases, we would expect learners to identify as unacceptable (L) (and consequently to correct) an increasingly larger number of sequences in the test passage. In fact, as the top curve in Figure 4 indicates, this expected increase did not occur. The average number of total errors (L) remained surprisingly consistent for students at all levels. The students were not told how many errors to expect -and were thus not overtly constrained as to the number of errors to be identified. It may well be, however, that some more subtle constraints are inherent in the task. The length of the passage, for example, may somehow have constrained the students to limit the number of errors they identified.

In summary, Corder's model of changes in the transitional competence of second language learners proved accurate to the extent that such changes are reflected in learners' judgments of acceptability. Schachter's predicted decrease of indeterminacy of learner judgments was not confirmed by the present study, although the present study certainly does not provide adequate grounds for a rejection of Schachter's proposal. Experimental evidence in applied linguistics must always be interpreted cautiously. However, the present study suggests that the progress of change in learner judgments is subject to experimental investigation and that the results of such experiments together with other sorts of evidence can advance our understanding of how second language learning progresses.

\section{REFERENCES}

Arthur, Bradford. 1980. Language judgments as evidence for the structure of language competence. Unpublished manuscript.

Corder, S. Pit. 1971. Idiosyncratic dialects and error analysis. IRAL 9.2.

d'Anglejan-Chatillon, A. 1975. Dynamics of second language development: a search for linguistic regularity. Ph.D. Dissertation, McGill University, Montreal. 
Dulay, H., and M. Burt. 1974. Natural sequences in child second language acquisition. Language 24.1.

Ravem, Roar. 1974. Second language acquisition: a study of two Norwegian children's acquisition of English syntax in a naturalistic setting. Ph.D. Dissertation, University of Essex.

Schachter, Jacquelyn, Adele F. Tyson, and Frank J. Diffley. 1976. Learner intuitions of grammaticality. Language Learning 26.1.

Swain, M. 1976. Changes in errors: random or systematic? Proceedings of the Fourth International Congress of Applied Linguistics. Stuttgart: Hochschul Verlag.

Tarone, Elaine, U. Frauenfelder, and Larry Selinker. 1976. Systematicity/variability and stability/instability in interlanguage systems. Language Learning (Special Issue).

Tucker, G. Richard, and Marian Sarofim. 1979. Investigating linguistic acceptability with Egyptian EFL students. TESOL Quarterly 13.1. 